\title{
Bio Control Potential of Rice Endophyte Fusarium oxysporum Against Rice Sheath Blight Pathogen Rhizoctonia solani
}

\author{
Divya R, Aju K Asok and Jisha MS* \\ School of Biosciences, Mahatma Gandhi University, India
}

Submission: December 05, 2017, Published: December 11, 2018

"Corresponding author: Jisha MS, Associate Professor, School of Biosciences, Mahatma Gandhi University, India

\begin{abstract}
Discovering novel and effective microbial strains for increasing plant productivity; by enhancing the availability of utilizable minerals and by inhibiting an array of bacterial and fungal pathogens to plant is innovative approach in sustainable agriculture. There is particular interest in growing crops with little or no dependence on chemical pesticides and placing considerable weight on biological control. Fungal endophytes are a group of microorganisms associated with plants and have attracted a great interest to botanist, microbiologist and ecologist. In this study endophytic fungi were isolated from rice and were evaluated for their antagonism against Rhizoctonia solani, an important rice pathogen causing Sheath Blight disease in rice.
\end{abstract}

Keywords: Endophytic microorganisms; Graminaceous crops; Oryza sativa; Fungal pathogens; Phytochemistry; Antioxidant agents

Abbreviations: ShB: Sheath blight; PDA: Potato Dextrose Agar; ITS: Transcribed Spacer regions

\section{Introduction}

An endophyte is a fungal or bacterial microorganism that spends the whole or part of its life cycle colonizing healthy tissues of the host plant, typically causing no apparent symptoms of disease [1]. The relationship between the host and the endophyte may range from symbiotic to near pathogenic [2]. Endophytic microorganisms are a significant reservoir of genetic diversity, and an important source for the discovery of novel bioactive secondary metabolites. Endophytes are a rich source of natural products displaying a broad spectrum of biological activities and the phytochemistry of endophytic microbes continues to increase in significance. As a general rule, a single endophytic strain will produce multiple bioactive substances. The reported natural products from endophytes include antibiotics, antipathogens, immunosuppressants, anticancer compounds, antioxidant agents and other biologically active substances. Many medicinal plants are reported to be harboring endophytic fungi.

The ecological roles played by endophytic fungi are diverse and varied [3]. Besides protection against insects, many of these fungi produce biologically active secondary metabolites [4]. Certain, other metabolites produce host growth responses, accelerate or delay senescence [3]. Future investigations might include studies aimed at detecting production of antibiotics and pest deterrents in plants as a first step towards evaluating ecological significance of secondary metabolite production by endophytes in biological control.
Rice (Oryza sativa), one of the primary graminaceous crops, constitutes the main nutrient resource for $40 \%$ of world's population including most developing countries. Rice has been severely affected by several diseases and insect pests, of which Sheath blight (ShB) disease caused by Rhizoctonia solani is becoming a serious concern for the successful cultivation of rice. It is one of the most destructive diseases of rice that occurs globally [5]. Abuse of chemical pesticides, which are the most common approach for control, can destroy the balance of eco systems and the contamination by their toxic residues may cause harm to humans and domestic animals. In addition, chemicals can decrease the soil micro flora sharply and induce tolerance of the pathogens. Search for environmentally and toxicologically safe, more selective and efficacious fungicides for the control of plant diseases is gaining momentum at present. As an environmentally benign agent, endophytes are the ideal candidates. The aim of the present study is to isolate potential endophytic fungi from paddy (Oryza sativa)which will be effective against Rhizoctonia solani, an important rice pathogen causing Sheath blight disease in paddy.

\section{Materials and Methods}

\section{Rice Plant Samples}

Rice plants were collected from Kottayam, Alapuzha and Trivandrum districts, Kerala. Ten rice plants without signs of any disease were collected from four plots of one experimental field. 
Samples should be air dried to remove any surface moisture before transport or storage. During transport, it should be kept cool and dry. Paper bags were used. Samples were processed as quickly as possible following collection usually within 24 hours.

\section{Tested Pathogen and Culture Condition}

Rhizoctonia solani, isolated from infected rice was provided by Rice Research Institute, Mancombu, Kerala. The cultures were frequently sub-cultured and maintained in Potato Dextrose Agar (PDA) medium.

\section{Sample preparation}

A vigorous prewashing of plant material was performed to reduce the number of surface microflora and soil. This increases the effectiveness of the surface sterilizer. Prewash was done using running tap water. Samples were surface sterilized using $\mathrm{NaOCl}$ solution for 5 minutes [6]. Finally they were rinsed three times in sterile distilled water. The surface sterilized samples were cut into $1 \mathrm{~cm}$ fragments. The flow out after washing the surface sterilized samples with sterilized water was plated on PDA plate and incubated at room temperature. A control plate with medium was also incubated along with it.

\section{Isolation of endophytic fungi}

The surface-sterilized samples were cut into $1 \mathrm{~cm}$ fragments Ten fragments from different parts of leaves per rice sample were placed on YEG agar medium. These plates were incubated at $25^{\circ} \mathrm{C}$ for 8-12 days. Hyphal tips of the developing fungal colonies were transferred onto PDA. After purifying the isolates several times, the final pure cultures were transferred to PDA slant tubes.

\section{Identification of fungal endophytes}

Isolates from slants were transferred to PDA medium on a sterile microscopic slide, which was then covered with a sterile cover glass, incubated at $25^{\circ} \mathrm{C}$ and periodically the fungal fruiting structures were observed by microscope using lactophenol cotton blue staining. Further identification of fungal endophyte was achieved by amplification of Internal Transcribed Spacer regions (ITS) in conjunction with $18 \mathrm{~S}$ rDNA sequencing. The DNA was isolated and ITS region was PCR amplified with ITS1 and ITS 2 primers.

Amplicon was electrophoresed in a $1 \%$ Agarose gel and visualized under UV. Concentration of the amplicon was checked in a Nanodrop ND 2000. The amplicon was purified using Nucleospin purification column (Macherey-Nagel). Sequencing of amplicon with forward and reverse ITS primers in ABI 3730xl cycle sequencer. Forward and reverse sequences were assembled and contig was generated after trimming the low quality bases. The sequence analysis was carried out using bioinformatic tool BLAST of NCBI. Based on maximum identity score first few sequences were selected and aligned using multiple sequence alignment software Clustal W. Dendrogram was constructed using neighbor joining method.

\section{In vitro evaluation of antagonistic potential of the endo- phytes (Dual plate assay)}

Isolated endophytic fungi were screened for their antagonistic ability against an important plant pathogen, Rhizoctonia solani (Sheath Blight of rice) by the dual culture technique. Petri dishes with the growth medium were simultaneously inoculated with $9 \mathrm{~mm}$ disc of the pathogen as well as antagonist near the periphery at diametrically opposite points. Periodic observations are made at regular intervals on the linear growth $(\mathrm{mm})$ of the antagonist colonizing the pathogen's growth.

\section{Results and Discussion}

This study was done to isolate endophytic fungus from rice and was evaluated for their antagonism against Rhizoctionia solani, an important rice pathogen causing Sheath Blight disease in rice. Endophytic fungi were isolated from the plant materials after eight to twelve days of incubation. The identification of the endophytic fungi was done by colour, texture, pigmentation and morphology of the colonies and the Lactophenol cotton blue staining of the conidiophores.

The colony of first isolate was wooly and eventually covered by grayish, short, aerial hyphae. The conidiophores were mostly unbranched. The conidia were ellipsoidal with short cylindrical beak with muriform septation. This isolate was identified as Alternaria sp. The colony of the second isolate was wooly and black in colour. The conidia was 4-5 cells separated by transverse septa formed from twisted conodiophores, the characteristic feature of Curvularia sp. The third isolate produced black colour colony with vesicle bearing conidia. Conidia were in single or paired resemble yeast cells, chains or detached and dispersed. This isolate was identified as Aspergillus sp. The colony of the fourth isolate were cottony pinkish white. Conidia were thin walled, three to five septate, fusoid and pointed at both ends. This isolate was identified as Fusarium sp.

Isolated endophytic fungi were tested for antagonistic activity by dual culture method. The isolated Fusarium sp. significantly inhibited the growth of Rhizoctionia solani and the percentage of inhibition was found to be $90.5 \%$. The level of antagonism exhibited by Fusarium oxysporum against test pathogen Rhizoctonia solani was very high. It showed strong inhibition of mycelia growth of plant pathogenic fungi. The present study describes a novel potential endophyte isolated from rice (Oryza sativa L.) that appears to be quite effective in inhibiting Rhizoctionia solani and contributes enhanced productivity.

Molecular analysis of fungal rDNA at the sequence level provides a powerful technique for assessing fungal diversity at the genus level. The molecular analysis of the isolated endophytic fungus with antagonistic property during the study found that the endophyte is Fusarium oxysporum.

Novelty of the endophytic association is its ability to colonize different host plants and tissues. It was found that it can control the Sheath blight disease in rice. In the preliminary studies, [7], 
reported that exploitation of the endophytes as biocontrol agents may be a breakthrough in the biological control adding strength to additional benefits of host/fungus endophytic association [8].

\section{References}

1. Strobel GA (2002) Microbial gifts from rain forests. Can J Plant Pathol 24: 14-24.

2. Sturz AV, Nowak J (2000) Endophytic communities of rhizobacteria and the strategies required to create yield enhancing associations with crops. Appl. Soil Ecol 15: 183-190.

3. Saikkonen K, Faeth SH, Helander M, Sullivan TJ (1998) Fungal endophytes: a continuum of interactions with host plants. Ann Rev Ecol 29: 319-343.

4. Pelaez F, Collado J, Arenal F (1998) Fungal endophytes of tree leaves. Microbial ecology. pp: 179-197.
5. Slaton NA, Cartwright RD, Meng J, Gbur EE Jr, Norman RJ (2003) Sheath Blight severity and rice yield as affected by nitrogen fertilizer rate, application method and fungicide. Agronomy Journal 95(6): 14891496.

6. Schulz BU, Draeger S, Aust HJ (1993) Endophytes from herbaceous plants and shrubs: Effectiveness of surface sterilization methods. Mycol Res 97: 1447.

7. Mathivanan N, Prabavathi VR, Vijayanandraj VR (2008) The effect of fungal secondary metabolites on bacterial and fungal pathogens. In: PetrKarlovsky (Ed.), Secondary metabolites in soil ecology. pp. 129140.

8. Vindhyasekharan P, Ruby P, Samiyappan R (1997) Host specific toxin production by $R$ solani, the rice sheath blight pathogen.

\section{Your next submission with Juniper Publishers will reach you the below assets}

- Quality Editorial service

- Swift Peer Review

- Reprints availability

- E-prints Service

- Manuscript Podcast for convenient understanding

- Global attainment for your research

- Manuscript accessibility in different formats

( Pdf, E-pub, Full Text, Audio)

- Unceasing customer service

Track the below URL for one-step submission https://juniperpublishers.com/online-submission.php 